\title{
Solid-State NMR Spectroscopy Reveals That Water is Nonessential to the Core Structure of Alpha-Synuclein Fibrils
}

\author{
Kathryn D. Kloepper ${ }^{1}$, Kevin L. Hartman ${ }^{1}$, Daniel T. Ladror ${ }^{1}$, and Chad M. Rienstra ${ }^{1,2,3,{ }^{*}}$ \\ 1Department of Chemistry, University of Illinois at Urbana-Champaign, Urbana, IL 61801 \\ 2Department of Biochemistry, University of Illinois at Urbana-Champaign, Urbana, IL 61801 \\ 3Center for Biophysics and Computational Biology, University of Illinois at Urbana-Champaign, Urbana, \\ IL 61801
}

\begin{abstract}
Protein aggregation is implicated in the etiology of numerous neurodegenerative diseases. An understanding of aggregation mechanisms is enhanced by atomic-resolution structural information, of which relatively little is currently available. Lewy bodies, the pathological hallmark of Parkinson's disease, contain large quantities of fibrillar alpha-synuclein (AS). Here we present solid-state NMR spectroscopy studies of dried AS fibrils. The spectra have high resolution and sensitivity, and the site-resolved chemical shifts agree very well with those previously observed for hydrated fibrils. The conserved chemical shifts indicate that bulk water is nonessential to the fibril core structure. Moreover, the sample preparation procedure yields major improvements in spectral sensitivity, without compromising spectral resolution. This advance will greatly assist atomic-resolution structural analysis of AS fibrils.
\end{abstract}

\section{Keywords}

amyloid; chemical shifts; magic-angle spinning; Parkinson's disease; protein

\section{Introduction}

The protein $\alpha$-synuclein (AS) is intrinsically unstructured yet upon prolonged incubation forms $\beta$-sheet rich amyloid fibrils, as found in the Lewy bodies of Parkinson's disease patients. 1,2 Mutations of AS (A53T,3 A30P, ${ }^{4}$ and E46K ${ }^{5}$ ) are implicated in familial PD, although the mechanism of pathology is not yet well understood. Structural information in this context is highly desirable. However, because amyloid fibrils are insoluble and non-crystalline, solution NMR and $x$-ray crystallography studies of fibrils are limited. Structural models have been developed based upon EPR spin labeling experiments. 6,7 Higher resolution information can be provided by solid-state NMR (SSNMR), as demonstrated in recent studies of $\beta$-amyloid, 8-11 HET-s prion, ${ }^{12-14}$ and $\mathrm{AS}^{15,16}$ fibrils. Obtaining spectra of high resolution and sensitivity is the first step towards total structure determination.

In the case of AS, as we recently demonstrated, ${ }^{16}$ relatively weak cross polarization (CP) signals are observed near room temperature, due to local molecular dynamics. Low temperature significantly enhances signal intensities while retaining high resolution. Nevertheless, the majority of the NMR rotor volume is occupied by water, placing an upper limit on the detection

\footnotetext{
*To whom correspondence should be addressed. E-mail: rienstra@scs.uiuc.edu Phone: 217 244-4655 Fax: 217 244-4655
} 
sensitivity. Further enhancements in sensitivity could be derived from drying fibrils, as previously demonstrated for $\beta$-amyloid, ${ }^{17}$ but to do so raises the concern that the dehydration process might alter the fibril structure. For example, Perutz et al. have modeled amyloid fibrils (including AS) as water-filled nanotubes. ${ }^{18}$ Experimental data that give insight into atomicresolution structural properties would help to resolve this controversy.

In this work, we present such insights based on SSNMR spectra of dried AS fibrils. We show that dried samples yield spectra with nearly identical chemical shifts to those of hydrated fibrils, consistent with an atomic-resolution structure that is unaltered upon dehydration. In addition, spectral sensitivity is substantially enhanced due to the larger quantity of dried protein packed into the SSNMR rotor. This protocol is applicable to high-resolution structural studies of AS fibrils.

\section{Experimental Section}

Expression, purification, and fibril formation of AS were performed as described previously. 16,19 Fibrils were separated from solution by ultracentrifugation at $100,000 \mathrm{~g}$ for $1 \mathrm{~h}$, and the supernatant removed. The centrifuged fibrils appeared as translucent, white gelatinous pellets. The mass of a fully hydrated fibril pellet (starting protein amount $=7.5 \mathrm{mg}$ ) was typically $50-60$ $\mathrm{mg}$. The pellet was dried under a gentle stream of $\mathrm{N}_{2}(g)$ until hard and white. The sample was weighed throughout the 2-4 h drying period in order to monitor water loss. The dried pellet was then crushed with a wooden dowel (to increase surface area) and again dried under a stream of $\mathrm{N}_{2}(g)$ until no further changes in mass were observed.

SSNMR studies were performed on four-channel Varian InfinityPlus spectrometers. Spectra of hydrated fibrils were acquired at $600 \mathrm{MHz}$ with a Varian Balun ${ }^{\mathrm{TM}}{ }^{1} \mathrm{H}-{ }^{13} \mathrm{C}-{ }^{15} \mathrm{~N} 4.0 \mathrm{~mm}$ probe and MAS rate of $10,000 \pm 3 \mathrm{~Hz} .{ }^{16}$ Experiments on dried fibril samples were acquired at $500 \mathrm{MHz}$ with a Varian Balun ${ }^{\mathrm{TM}}{ }^{1} \mathrm{H}_{-}{ }^{13} \mathrm{C}-{ }^{15} \mathrm{~N} 3.2 \mathrm{~mm}$ MAS probe at $11,111 \pm 3 \mathrm{~Hz}$. The variable temperature gas was maintained at $90 \pm 10 \mathrm{scfh}$ flow, and the reported sample temperatures take into account thermocouple calibration and frictional heating due to MAS. Data were processed with nmrPipe ${ }^{20}$ with back linear prediction and polynomial baseline (frequency domain) correction applied to the direct dimension, and zero filling and Lorentzian-to-Gaussian apodization were applied to each dimension before Fourier transformation; processing parameters are located in the figure captions. Chemical shifts are referenced to adamantane. ${ }^{21}$ Linewidths are reported for 25 representative ${ }^{15} \mathrm{~N}$ and ${ }^{13} \mathrm{C}$ sites.

\section{Results and Discussion}

\section{FIGURE 1}

As demonstrated previously, fully hydrated AS fibrils yield relatively weak CP signals near room temperature, due to molecular motions that dynamically average dipolar couplings. 16 The $1 \mathrm{D}{ }^{13} \mathrm{C}$ CP-MAS spectra of hydrated AS fibrils are enhanced substantially by reduction in temperature from 0 to $-40{ }^{\circ} \mathrm{C}$. Here we show that spectra of dried AS fibrils are essentially independent of temperature in this regime (Figure 1). The integrated spectral intensity varies by less than $5 \%$ over this range. We attribute this to the rigidity of the dried protein. $\mathrm{CP}$ enhancement values of $\sim 2.5$ for the ${ }^{1} \mathrm{H}-{ }^{13} \mathrm{C}$ versus ${ }^{13} \mathrm{C}$ Bloch decay (direct polarization) spectra further support this interpretation; such enhancements are observed on our instruments only for microscopically rigid proteins or model organic compounds. ${ }^{22,23}$ In contrast, spectra of hydrated fibrils 16 have poor $\mathrm{CP}$ enhancement $(\sim 1.0)$ at $0^{\circ} \mathrm{C}$, which increases somewhat to 2.2 at $-40{ }^{\circ} \mathrm{C}$. Therefore sample drying improves $\mathrm{CP}$ enhancement.

A second benefit of drying is that a larger quantity of protein can be packed in the rotor. We examined hydrated samples primarily in $4 \mathrm{~mm}$ limited speed rotors, in which at most $\sim 14 \mathrm{mg}$ 
of protein could be packed (approximately $16 \%$ by mass), with the remainder water. Limited speed $3.2 \mathrm{~mm}$ rotors allow for only $\sim 7 \mathrm{mg}$ of hydrated protein; however, upon drying, more than $24 \mathrm{mg}$ of protein was packed in the same $3.2 \mathrm{~mm}$ rotor model. The large quantity of material in the smaller coil volume, combined with the enhanced $\mathrm{CP}$, resulted in a greater than four-fold sensitivity gain per unit time.

FIGURE 2

${ }^{2 D}{ }^{13} \mathrm{C}-{ }^{13} \mathrm{C}$ spectra (Figure 2) have similar spectral fingerprints. For example, the patterns of Thr, Ser, Gly, Ala and Ile cross peaks (as indicated on the figure) are qualitatively similar in both spectra. The overall appearance does differ, due to the fact that the dried AS spectra have much greater overall intensity. This is especially significant among side-chain resonances, such as Glu CB/CG-CD and Asp CB-CG (F1 = 180-185, F2 = 30-40 ppm). Many peaks appear in this dried fibril spectrum that could only be observed with more than a day of signal averaging with the hydrated fibrils. Such 2D spectra were also used to confirm that of the drying procedure was readily reproduced and the samples have indefinite stability.

FIGURE 3

We acquired 3D spectra to identify backbone correlations for the unambiguous assignment of $\mathrm{N}, \mathrm{C}^{\prime}, \mathrm{CA}$ and side-chain ${ }^{13} \mathrm{C}$ chemical shifts; NCOCX, CAN(CO)CX, NCACX, and CON (CA)CX spectra were acquired in $20 \mathrm{~h}$ each (Figure 3) using methods described elsewhere. 23 Signal positions were consistent with those previously reported, and the line widths $(0.58$ $\pm 0.15 \mathrm{ppm}$ in the ${ }^{13} \mathrm{C}$ dimensions and $0.96 \pm 0.26 \mathrm{ppm}$ for ${ }^{15} \mathrm{~N}$ ) were within error the same as those of hydrated fibrils. This indicates that the drying procedure caused no significant deterioration in microscopic order of the fibril core.

FIGURE 4

We proceeded to assign the majority of resonances in the fibril core from V66 to F94 (Supporting Information), enabling a site-specific comparison of hydrated and dried AS fibrils. The chemical shift values are highly correlated between the two states (Figure 4). For example, the correlation coefficient $\left(\mathrm{R}^{2}\right)$ for ${ }^{15} \mathrm{~N}$ chemical shifts is 0.984 , and the root-mean-squared deviation (RMSD) of the ${ }^{15} \mathrm{~N}$ chemical shifts is $0.88 \mathrm{ppm}$, slightly less than the average ${ }^{15} \mathrm{~N}$ linewidth. The aliphatic ${ }^{13} \mathrm{C}$ sites (CA and CB) agree with an even higher $\mathrm{R}^{2}$ value of 0.996 and RMSD of $0.89 \mathrm{ppm}$, and for the carbonyl ${ }^{13} \mathrm{C}$ values $\mathrm{R}^{2}$ is 0.965 and the RMSD $0.45 \mathrm{ppm}$, less than the average ${ }^{13} \mathrm{C}$ linewidth. The aliphatic ${ }^{13} \mathrm{C}$ chemical shifts depend most strongly upon backbone conformation, and therefore the high similarity indicates a conserved secondary structure. The most prominent outliers are S87 and I88, which (based on our previous TALOS analysis ${ }^{16}$ ) are likely in a turn. Excluding those sites, the overall RMSD for the other 68 assigned ${ }^{15} \mathrm{~N}$ and ${ }^{13} \mathrm{C}$ chemical shifts is $0.46 \mathrm{ppm}$. The agreement is remarkable when considering that the signals for the dried fibrils were assigned de novo.

\section{Conclusions}

SSNMR spectra of dried AS fibrils demonstrate that loss of water does not significantly alter the structure of the fibril core. The chemical shifts of the core region are identical within experimental error to hydrated AS fibrils. Therefore the secondary structure is not significantly changed by the dehydration process. Moreover, the common sidechain ${ }^{13} \mathrm{C}$ chemical shifts indicate that no major rearrangements of rotameric states occur. One significant difference observed is that dynamics are attenuated, as judged by a reduced temperature-dependent of the signal intensities. This is consistent with the periphery of the fibril becoming more tightly packed upon dehydration. 
In addition to the insights into AS secondary structure, the dried fibrils provide a benefit to sensitivity, as previously recognized for $\beta$-amyloid by Tycko and co-workers. ${ }^{17}$ Enhanced spectral sensitivity is particularly valuable for multidimensional experiments in which multiple polarization transfer steps are involved. Here we obtained optimal pulse sequence performance for several 3D experiments, enabling independent assignment of the fibril core with only a few days of experimental data. We anticipate that these same characteristics will enable experiments for measurements of long-range distances, which require high power decoupling. 24

Together these capabilities will contribute to the determination of AS fibril structures at atomic resolution, in order to relate the structure to functional properties of AS fibrils. This information will, in turn, enable elucidation of the role(s) that this protein plays in the etiology and/or progression of Parkinson's disease.

\section{Supplementary Material}

Refer to Web version on PubMed Central for supplementary material.

\section{Acknowledgement}

We thank the National Institutes of Health (R01GM073770) for funding, Dr. Donghua H. Zhou, W. Trent Franks, and Prof. Julia M. George for insightful discussions, and Prof. Beat H. Meier (ETH-Hönggerberg) for advice regarding fibril sample drying. K.D.K. was a James R. Beck Fellow.

\section{References}

(1). Conway KA, Harper JD, Lansbury PT. Biochemistry 2000;39:2552. [PubMed: 10704204]

(2). Spillantini MG, Schmidt ML, Lee VMY, Trojanowski JQ, Jakes R, Goedert M. Nature 1997;388:839. [PubMed: 9278044]

(3). Polymeropoulos MH, Lavedan C, Leroy E, Ide SE, Dehejia A, Dutra A, Pike B, Root H, Rubenstein J, Boyer R, Stenroos ES, Chandrasekharappa S, Athanassiadou A, Papapetropoulos T, Johnson WG, Lazzarini AM, Duvoisin RC, DiIorio G, Golbe LI, Nussbaum RL. Science 1997;276:2045. [PubMed: 9197268]

(4). Kruger R, Kuhn W, Muller T, Woitalla D, Graeber M, Kosel S, Przuntek H, Epplen JT, Schols L, Riess O. Nat. Genet 1998;18:106. [PubMed: 9462735]

(5). Zarranz JJ, Alegre J, Gomez-Esteban JC, Lezcano E, Ros R, Ampuero I, Vidal L, Hoenicka J, Rodriguez O, Atares B, Llorens V, Tortosa EG, del Ser T, Munoz DG, de Yebenes JG. Ann. Neurol 2004;55:164. [PubMed: 14755719]

(6). Der-Sarkissian A, Jao CC, Chen J, Langen R. J. Biol. Chem 2003;278:37530. [PubMed: 12815044]

(7). Chen M, Margittai M, Chen J, Langen R. J. Biol. Chem 2007;2007:24970. [PubMed: 17573347]

(8). Balbach JJ, Petkova AT, Oyler NA, Antzutkin ON, Gordon DJ, Meredith SC, Tycko R. Biophys. J 2002;83:1205. [PubMed: 12124300]

(9). Petkova AT, Ishii Y, Balbach JJ, Antzutkin ON, Leapman RD, Delaglio F, Tycko R. Proc. Natl. Acad. Sci. USA 2002;99:16742. [PubMed: 12481027]

(10). Petkova AT, Yau WM, Tycko R. Biochemistry 2006;45:498. [PubMed: 16401079]

(11). Petkova AT, Leapman RD, Guo ZH, Yau WM, Mattson MP, Tycko R. Science 2005;307:262. [PubMed: 15653506]

(12). Ritter C, Maddelein ML, Siemer AB, Luhrs T, Ernst M, Meier BH, Saupe SJ, Riek R. Nature 2005;435:844. [PubMed: 15944710]

(13). Siemer AB, Ritter C, Steinmetz MO, Ernst M, Riek R, Meier BH. J. Biomol. NMR 2006;34:75. [PubMed: 16518695]

(14). Siemer AB, Arnold AA, Ritter C, Westfeld T, Ernst M, Riek R, Meier BH. J. Am. Chem. Soc 2006;128:13224. [PubMed: 17017802] 
(15). Heise H, Hoyer W, Becker S, Andronesi OC, Riedel D, Baldus M. Proc. Natl. Acad. Sci. USA 2005;102:15871. [PubMed: 16247008]

(16). Kloepper KD, Zhou DH, Li Y, Winter KA, George JM, Rienstra CM. J. Biomol. NMR. 2007in press

(17). Bu Z, Shi Y, Callaway DJE, Tycko R. Biophys. J 2007;92:594. [PubMed: 17056725]

(18). Perutz MF, Finch JT, Berriman J, Lesk A. Proc. Natl. Acad. Sci. USA 2002;99:5591. [PubMed: 11960014]

(19). Kloepper KD, Woods WS, Winter KA, George JM, Rienstra CM. Protein Express. Purif 2006; $48: 112$.

(20). Delaglio F, Grzesiek S, Vuister GW, Zhu G, Pfeifer J, Bax A. J. Biomol. NMR 1995;6:277. [PubMed: 8520220]

(21). Morcombe CR, Zilm KW. J. Magn. Reson 2003;162:479. [PubMed: 12810033]

(22). Franks WT, Zhou DH, Wylie BJ, Money BG, Graesser DT, Frericks HL, Sahota G, Rienstra CM. J. Am. Chem. Soc 2005;127:12291. [PubMed: 16131207]

(23). Franks WT, Kloepper KD, Wylie BJ, Rienstra CM. J. Biomol. NMR. 2007in press

(24). Jaroniec CP, Filip C, Griffin RG. J. Am. Chem. Soc 2002;124:10728. [PubMed: 12207528]

J Phys Chem B. Author manuscript; available in PMC 2008 November 29. 

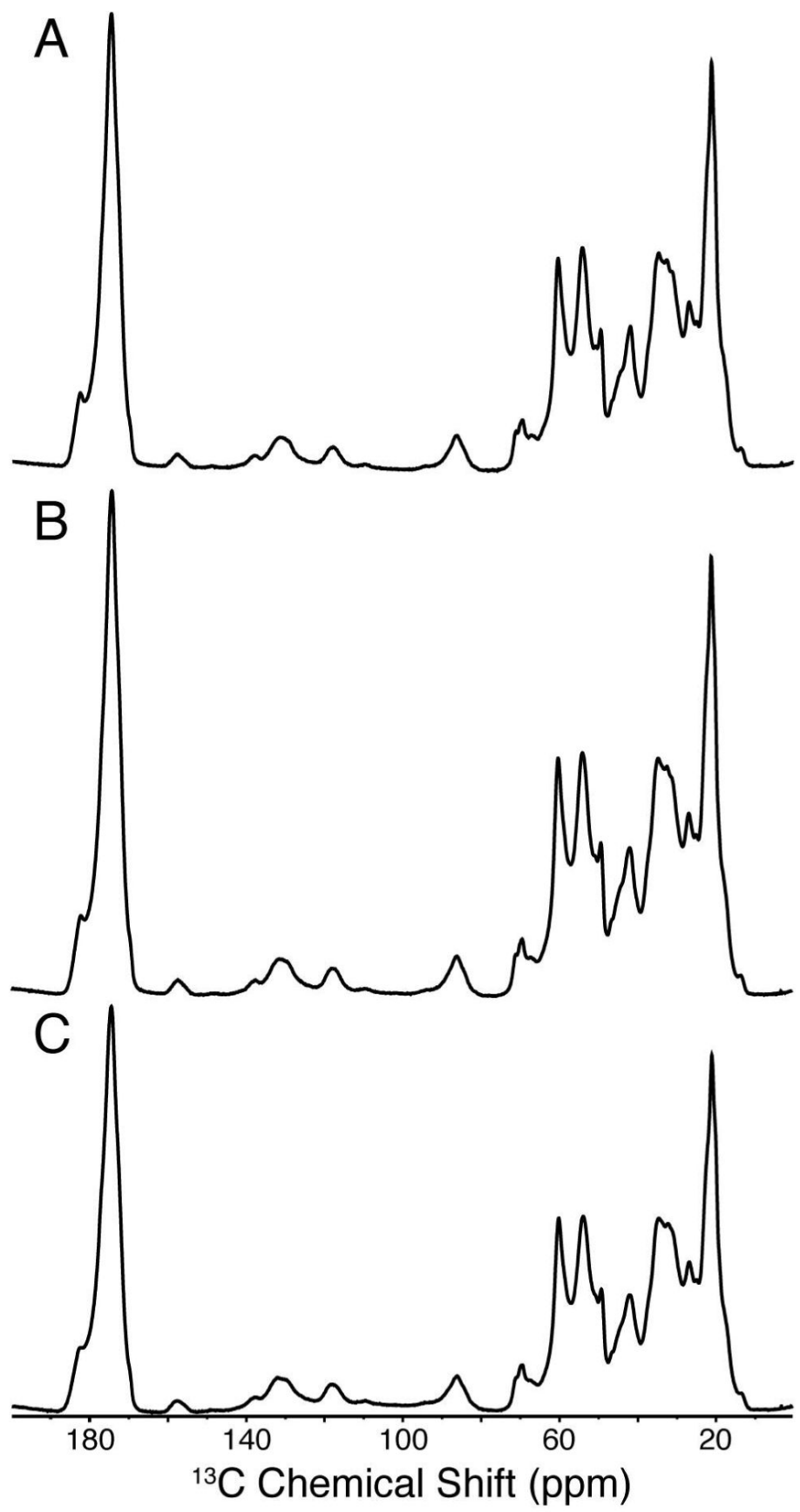

Figure 1.

${ }^{13} \mathrm{C}$ 1D spectra of dried AS fibrils, 384 scans. A) $\left.\left.0{ }^{\circ} \mathrm{C}, \mathrm{B}\right)-20{ }^{\circ} \mathrm{C}, \mathrm{C}\right)-40{ }^{\circ} \mathrm{C}$. All spectra are processed identically, with $0.16 \mathrm{ppm}$ line broadening. 


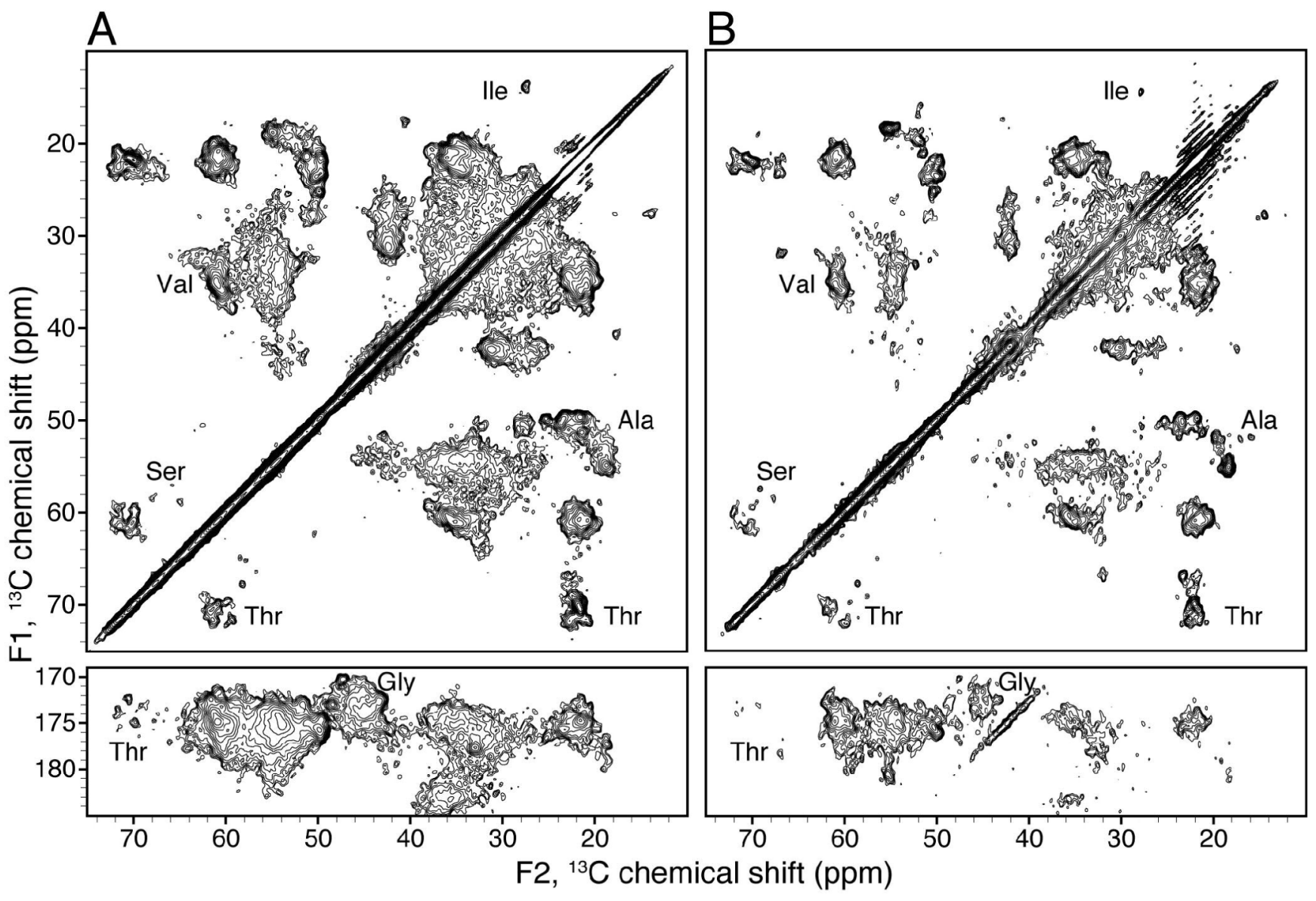

Figure 2.

Comparison of 2D CC (10 ms DARR mixing) spectra of AS fibrils. A) Dried AS fibrils acquired on a $500 \mathrm{MHz}$ spectrometer, $\sim 30 \mu \mathrm{l}$ sample volume, $1.7 \mathrm{~h}$ at $0{ }^{\circ} \mathrm{C}$; B) Hydrated AS fibrils acquired on a $600 \mathrm{MHz}$ spectrometer, $\sim 100 \mu \mathrm{l}$ sample volume, $2.2 \mathrm{~h}$ at $-40{ }^{\circ} \mathrm{C}$. Both spectra were processed identically, with $0.26 \mathrm{ppm}$ line broadening in both dimensions, and drawn with contours 5 times the noise level. 


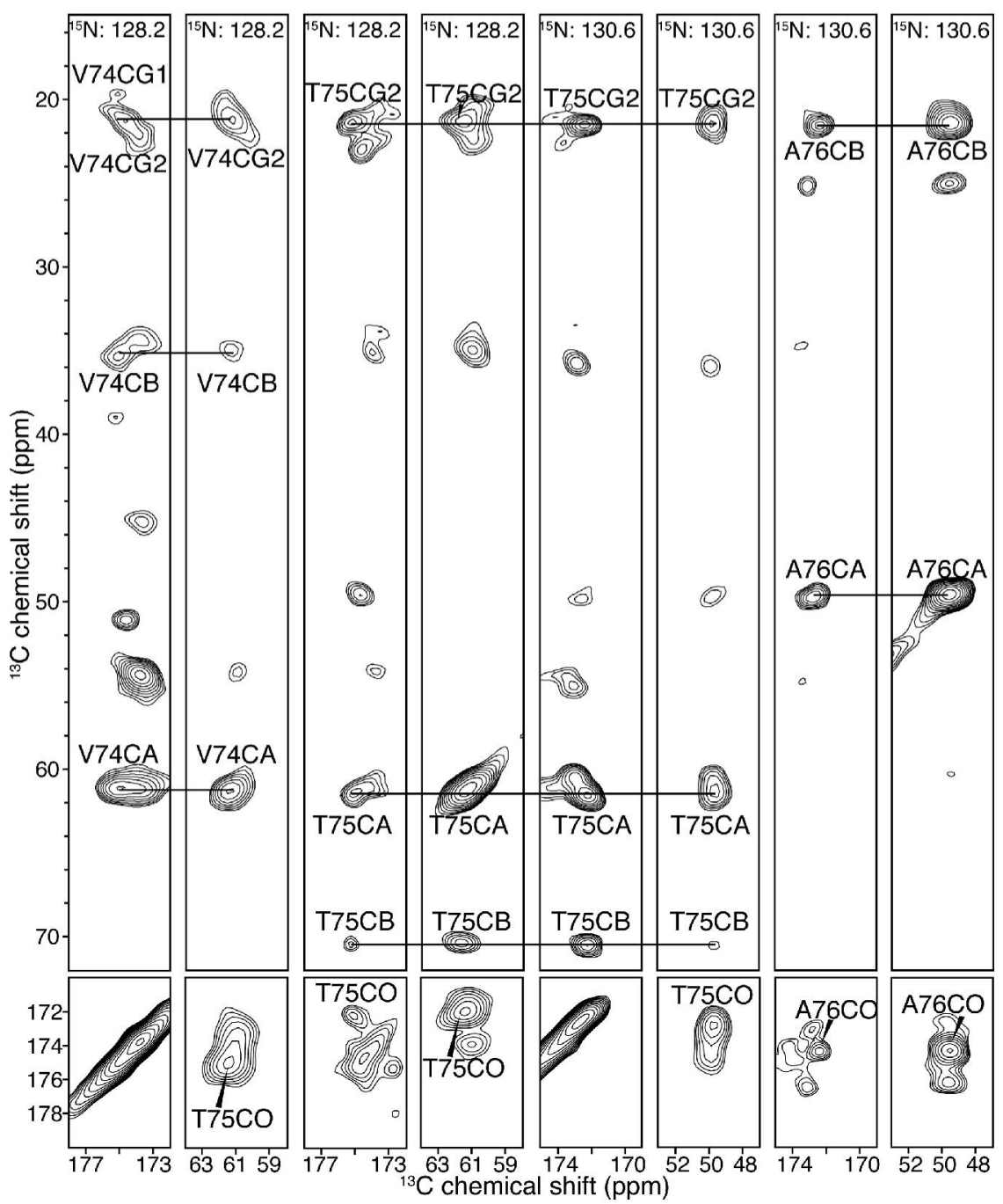

Figure 3.

Strip plot of 3D NCC/CNC type experiments demonstrating the backbone walk from V74 to A76. Spectra from left to right are NCOCX, CAN(CO)CX, CON(CA)CX, and NCACX 3Ds. Experiment time for each was $20 \mathrm{~h}$. 

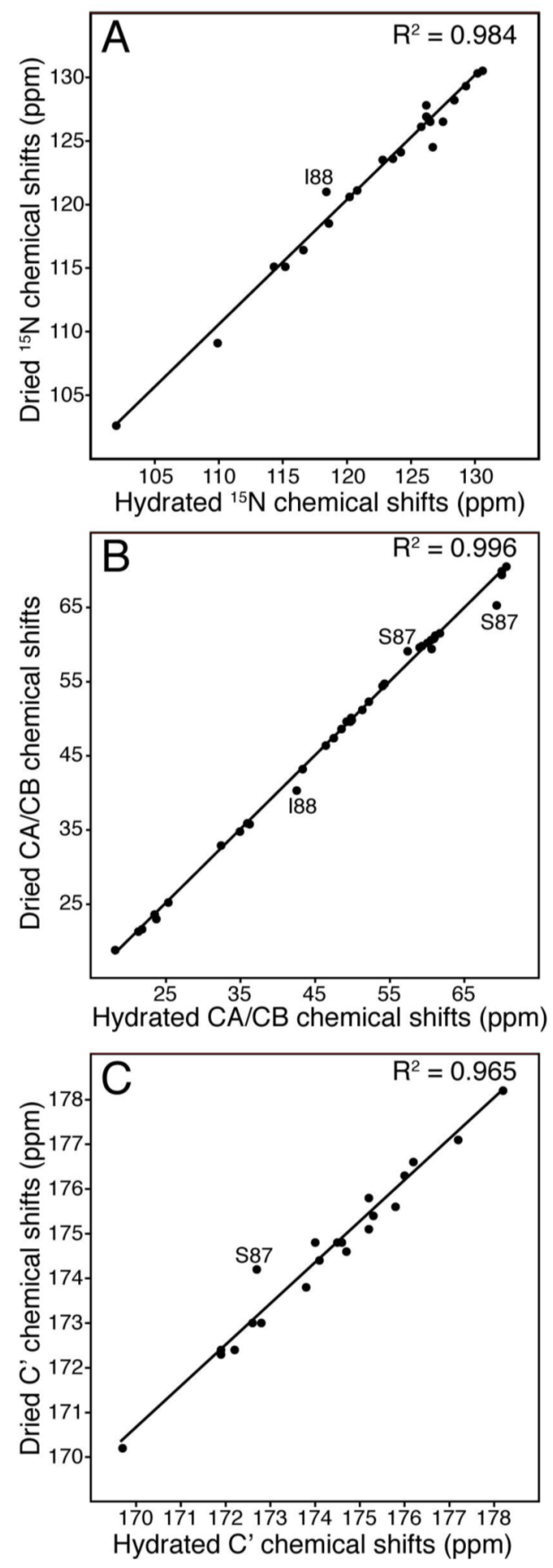

Figure 4.

Correlation of chemical shifts between hydrated and dried AS fibrils. 